\title{
REPRESENTAÇÕES DA OBESIDADE NO CINEMA: O "BURGUÊS GORDO" EM A GREVE (1925) DE EISENSTEIN
}

\author{
REPRESENTATIONS OF OBESITY IN CINEMA: THE 'FAT BOURGEOIS' IN \\ EISENSTEIN'S STRIKE (1925)
}

\begin{abstract}
REPRESENTACIONES DE LA OBESIDAD EN EL CINE: EL "BURGUÉS GORDO" EN LA HUELGA (1925) DE EISENSTEIN
\end{abstract}

Cezar Barbosa Santolin*, Luiz Carlos Rigo**

Palavras chave: Obesidade.

História.

Filmes cinematográficos.
Keywords: Obesity. History. Motion pictures.

Palabras clave: Obesidad. Historia. Películas cinematográficas.
Resumo: $O$ objetivo deste ensaio foi analisar o filme A greve (1925), de Sergei M. Einsenstein, como fonte primária da história das representações da obesidade no cinema. Utilizou-se a metodologia da análise discursiva da enunciação, numa perspectiva foucaultiana. Após assistir ao filme, identificaram-se quatro trechos considerados relevantes. Com as análises, constituíram-se dois enunciados: 1) os burgueses são corpulentos e gordos; e 2) os burgueses gordos são irascíveis. Ambos os enunciados indicam uma situação oposta à contemporaneidade, quanto às características atribuídas à obesidade e associadas a grupos socioeconômicos. Além disso, reforça a tese de que houve uma politização da corporeidade no processo histórico de inversão valorativa da condição denominada, naquele tempo, corpulência. Concluiu-se que o cinema pode ter sido uma ferramenta de propaganda ideológica fundamental na difusão desses novos valores, que podem ser identificados na contemporaneidade.

\begin{abstract}
This essay analyzes Sergei Eisenstein's film 'Strike' (1925) as the primary source for a history of representations of obesity in Cinema. As a method, it used discursive analysis of the enunciation from a Foucauldian perspective. After watching the movie, four passages were considered relevant and two enunciations were established: (1) the bourgeois are corpulent and fat; and 2) the fat bourgeois are irascible. Regarding the characteristics attributed to obesity in terms of socioeconomics groups, both statements indicate a situation that is opposite to today's. The results reinforce the view that there was politicization of corporeity in the historical process of inversion of values of the denominated condition - at that time, corpulence. As a conclusion, cinema may have been an ideological propaganda tool to spread the new values, which can be found in the contemporaneity.
\end{abstract}

Resumen: El objetivo de este ensayo fue analizar la película "La huelga" (1925), de Sergei Einsenstein, como fuente primaria de la historia de las representaciones de la obesidad en el cine. Se utilizó la metodología del análisis discursivo de la enunciación, en una perspectiva foucaultiana. Después de assistir la pelicula, se identificaron cuatro fragmentos considerados relevantes y se constituyó dos enunciados: 1) los burgueses son corpulentos y gordos; y, 2) los burgueses-gordos son irascibles. Ambos indican una situación opuesta a la contemporaneidad, cuanto a las características atribuidas a la obesidad y a grupos socioeconómicos. Además, refuerza la tesis de que hubo una politización de la corporeidad en el proceso histórico de inversión valorativa de la condición denominada, en aquel entonces, corpulencia. Se concluyó que el cine pudo haber sido una herramienta de propaganda ideológica fundamental en la difusión de esos nuevos valores, que pueden ser identificados en la contemporaneidad.
*Universidade Federal do Mato Grosso do Sul (UFMS). Campo Grande, MS, Brasil.

E-mail: cezarsantolin@ hotmail.com

**Universidade Federal de Pelotas (UFPel). Pelotas, RS, Brasil. E-mail: rigoperini@gmail.com

Recebido em: 12-04-2019 Aprovado em: 20-06-2019 Publicado em: 25-11-2019

DOI: https://doi.org/10.22456/1982-8918.91815 (c) (i) () Licence 


\section{INTRODUÇÃO}

No processo histórico de patologização da obesidade, ocorreram certas associações espúrias entre características corporais e outros aspectos, que nada tinham a ver com a questão, que anteriormente era por muitos considerada salutar, bela, poderosa e rica. Uma dessas influências foi político-ideológica, que originalmente deu-se na Inglaterra, no século XVIII, no âmbito das disputas entre tories e whigs (SANTOLIN; RIGO, 2015). Outras pesquisas, tais como as de Baecque (1989) e Martin (2009), reforçaram essa tese, ampliando as evidências históricas de uma politização do corpo - ou de uma incorporação da política - entre partidários da nobreza e antinobres, assim como entre direita e esquerda - respectivamente - no século XIX.

As fontes históricas, entretanto, sugeriam um alcance limitado dessas ancoragens simbólicas no corpo a grupos mais politizados de certos países europeus, não elucidando, entretanto, de que modo poderia ter ocorrido a difusão dos novos valores para o restante da sociedade e para outros países. Como ressaltado por Seixas e Birman (2012, p.14), "apesar da vasta produção médico-científica a respeito da obesidade, em poucas obras podemos identificar claramente sua construção histórica como uma categoria clínica". Mais raro ainda são pesquisas que tenham buscado investigar de que modo essa nova doença teria se difundido pela sociedade ao longo do século XX. Neste sentido, cogitou-se que o cinema poderia ter sido uma ferramenta de produção e divulgação, dado seu potencial propagandístico. Partindo dessa hipótese, buscaram-se fontes cinematográficas que replicassem o que fora encontrado em outros meios (SANTOLIN, 2012; SANTOLIN e RIGO, 2012a; 2015).

Pouco depois de sua aurora, no final do século XIX, o recém-criado cinematógrafo já era aparelhado para fins ideológicos diversos. Comumente, cita-se o filme Olympia, de 1938, da cineasta alemã Leni Riefenstahl, como um exemplar disso. Entretanto, não foram somente os nacional-socialistas ${ }^{1}$ que usaram esta ferramenta como instrumento de propaganda - os "internacional-socialistas" soviéticos também o fizeram bem antes desta data. Já em 1923, Trotski (citado por FERRO, 1992, p.27) escrevia: "O fato de até agora não termos ainda dominado o cinema prova o quanto somos desastrados e incultos, para não dizer idiotas. $O$ cinema é um instrumento que se impõe por si, é o melhor instrumento de propaganda". Ainda que já demonstrassem tal interesse, os comunistas só teriam realmente conseguido colonizar ideologicamente a produção cinematográfica por volta de 1927, sob o governo de Joseph Stálin (FERRO, 1992).

Essa instrumentalização se mostrou tão promissora e útil para a recente ditadura que, conforme Bernadet (1985), chegou-se a distribuir ingressos e tornar a ida dos companheirosoperários sovietes ao cinema uma obrigação. Mas, afinal, por que o cinema teria sido visto como uma ferramenta de propaganda ideológica tão privilegiada?

De acordo com Metz (1972, p.16), um filme "desencadeia no espectador um processo ao mesmo tempo perceptivo e afetivo de 'participação"', conquistando uma espécie de credibilidade imediata - uma sensação de "é assim", num enunciado plenamente afirmativo, como se não fosse uma representação, tornando-os poderosas ferramentas de convencimento. Por isso, propositalmente ou não, o cinema se constituiu como um dos agentes socioculturais ideológicos da história. 
Cabe ressaltar, entretanto, que a relação entre cinema e história não é tão óbvia e determinista - como pontuado por Ferro (1992) - pois, às vezes, os filmes não são agentes, mas somente reflexos de seu locus de emergência - de um tempo histórico, sociedade e cultura específicas. Em outras palavras, utilizando-se da bela metáfora proposta por Cousins (2011), o cinema pode ser um espelho do mundo - mas também pode ser um martelo - ou seja, às vezes, os filmes atuam num sentido crítico à realidade da qual emergem. Por isso, embora permaneça sempre certa ambiguidade a respeito dessa relação, os filmes podem ser constituídos como fontes relevantes também para a história da obesidade.

Assim, interessou-nos neste ensaio não diretamente o conteúdo político-ideológico, mas a propaganda de um outro tipo de ideia ou forma de verdade específica (FOUCAULT, 2005), a saber, a inversão valorativa atribuída à corpulência e à gordura corporal consideradas excessivas - que viria a ser, posteriormente, denominada obesidade.

Como ressaltado por Melo (2011), não são novas as discussões sobre as representações de determinados assuntos em filmes - tais como os esportes, as mulheres, os negros, os homossexuais, dentre outros. Pouco se discutiu, entretanto, a questão da história das representações cinematográficas da obesidade. Em vista disso, com intuito de contribuir para a historiografia da obesidade através do papel que o cinema teve enquanto ferramenta de propaganda ideológica, o presente ensaio buscou empreender uma análise do filme $A$ greve (1925), como uma peça deste grande quebra-cabeça.

\section{MATERIAIS E MÉTODOS}

As características deste ensaio permitem classificá-lo como uma pesquisa histórica (STRUNA, 2007). O filme-caso, constituído aqui enquanto fonte histórica primária, foi selecionado arbitrariamente, a título de projeto-piloto, por corresponder e se enquadrar na hipótese analítica de uma tese doutoral maior.

O filme se encontra em domínio público e pode ser acessado através do site public. domain movies (2018), assim como através da plataforma YouTube. Após o acesso, os dados foram analisados conforme a metodologia denominada análise da enunciação (BARDIN, 2011), mas na perspectiva de Michel Foucault (1989; 2008). Essa opção deu-se por se tratar de uma análise interessada nos enunciados presentes nos discursos, na composição de formações discursivas, sem adentrar a análise especificamente do campo psicanalítico.

Procedimentalmente, após assistir ao filme uma primeira vez, desenvolveu-se uma análise geral da obra, identificando o tema do filme e possíveis trechos que poderiam ser considerados relevantes para a temática em questão. Feito isso, tendo considerado o material relevante, realizou-se uma segunda visualização, na qual foram descritas com maior grau de detalhamento as passagens selecionadas, recorrendo ao uso do período do filme em que ocorrem devido à dificuldade de citação de seus conteúdos. Após isso, buscou-se constituir, a partir das descrições e interpretações, quais enunciados estariam presentes nas representações.

Dada a possibilidade de contestação crítica às análises e interpretações, devido às características inerentes à atividade hermenêutica, mantiveram-se citações aos períodos do filme analisados, assim como os argumentos que fundamentam as análises e a constituição dos 
enunciados, de modo que outros pesquisadores possam conferir as passagens e compartilhar ou não das interpretações realizadas².

\section{DESCRIÇÃO, ANÁLISE E DISCUSSÃO}

A greve (1925) foi escrito por Sergei Mikhailovitch Eisenstein, Grigoriy Aleksandrov, llya Kravchunovsky e Valerian Pletnev, sob direção do primeiro (IMDb, 2018). Por ter sido escrita e dirigida por Eisenstein (1898-1948), atribui-se, comumente, a autoria da obra a ele, que é considerado o cineasta-modelo do que ficou conhecido como cinema soviético - um conjunto de filmes produzidos no período após a Revolução Russa (1917) e que tinham forte viés político-partidário comunista.

Assim como os demais filmes desse movimento, as obras deste cineasta têm tipicamente conteúdos históricos, altamente enviesadas ${ }^{3}$ ideologicamente. Seus filmes reverberaram mundialmente, notabilizando-se principalmente por O encouraçado Potemkin (1925) e Outubro (1927) (JULLIER; MARIE, 2012).

Apesar de ser menos famoso, A greve (1925), originalmente, seria o primeiro de oito filmes, sob um título provisório de "Até a ditadura", constituindo-se como o mais importante projeto cinematográfico para Eisenstein (FIGUEIREDO, 2018). Conforme Figueiredo (2018), o filme é tanto a origem da carreira deste realizador quanto do próprio Cinema Soviético.

Trata-se, claramente, de uma peça de propaganda político-ideológica, tal como também fizera Joseph Goebbels - o ministro da propaganda de Hitler - no Nacional-Socialismo alemão. Para Figueiredo (2018), A greve é uma das mais poderosas obras propagandísticas da história do cinema. Mais importante para o presente estudo, entretanto, é o fato da obra ser também uma fonte histórica relevante para a história da obesidade, evidenciando a politização corporal no processo de nascimento de um discurso patologizante da obesidade.

A película é em preto e branco, muda, com música sem vinculação com os acontecimentos representados. Como o título sugere, a trama narra a história de uma greve - iniciada a partir do suicídio de um operário, acusado injustamente de roubar uma ferramenta - frustrada em seus objetivos, sendo fortemente reprimida e finalizada com 0 extermínio dos trabalhadores e suas famílias no bairro operário. Xavier (2014) considera o filme revolucionário, na medida em que expõe uma tática, explicita um processo de luta e analisa a produção de um ato revolucionário, ao invés de fornecer somente uma descrição de seus lances espetaculares.

A obra foi dividida formalmente em seis partes, intituladas: 1) Tudo está calmo na fábrica; 2) Uma razão para fazer greve; 3) A fábrica perde força; 4) A greve é desencadeada; 5) Provocação e desastre; e, 6) Extermínio. A composição é quase como um argumento, à moda dialética. Xavier (2014) chega a nomear a abordagem eisensteiniana de cinema-discurso, em que mesmo o enquadramento já compunha esse discurso pictórico-sonoro. Conforme essa perspectiva, o cinema seria um discurso e seria ideológico - um cinema que "pensa por

2 Para aqueles que não assistiram ao filme, talvez algumas interpretações possam soar inverossímeis. Assim, optamos por inserir ao texto alguns fotogramas. Para a produção destes, utilizou-se a ferramenta print screen.

3 Sobre o enviesamento, Eisenstein (citado por XAVIER, 2014, p.132) escreveu: "Ignorar o 'viés' e desperdiçar energia é o maior crime de nossa geração. Para mim, e em si mesmo, o viés tem um grande potencial artístico, embora não precise sempre ser tão político, ou tão conscientemente político, (...) Quando ele está completamente ausente, quando o filme é considerado como simples passatempo, sedativo e hipnótico, então esta ausência pode ser interpretada como realmente 'enviesada', na manutenção da tranquilidade e no deixar a plateia satisfeitas com as condições como estão". 
imagens" (p.133), um "cine-dialética" ou "cinema intelectual", em que a percepção visual está organizada para projetar uma reflexão sobre a ação prática.

Eisenstein foi não somente um cineasta pioneiro na história do cinema, mas também um dos primeiros a teorizar e explorar possibilidades narrativas, como, neste caso, a constituição de um personagem-coletivo (os operários), contraposto ao personagem-indivíduo (o patrãoburguês: 0 diretor), ambos atuando enquanto estereótipos - interpretação corroborada tanto por Figueiredo (2018) quanto por Fonseca e Paiva (2017). Sabe-se que há preferência na retórica propagandista comunista por agentes históricos coletivos, tal como no lema "trabalhadores do mundo, uni-vos" (MARX; ENGELS, 2018).

Para Gomes (2006), a obesidade pode ser considerada uma metáfora das ambivalências da contemporaneidade, já que a própria sociedade "criaria" o obeso, mas depois o culpabilizaria pela condição. Abordagens individualizantes e populistas, como a de Eisenstein, no início do século XX, podem ter contribuído para a formação desta tendência - se aceitarmos a premissa de que o presente é - em alguma medida - um produto do passado.

O filme foi endereçado (ELLSWORTH, 2001) aos proletários - tanto soviéticos quanto dos demais países, tendo em vista as intenções internacionais dos revolucionários, alcançando um sucesso gigantesco ${ }^{4}$ na sociedade russa da época (FIGUEIREDO, 2018).

Quanto ao tema que nos interessa, há quatro sequências que foram consideradas relevantes. O primeiro trecho corresponde ao segundo plano do filme, com duração de 4 s., com início em 1 min. $33 \mathrm{~s}$. Mostra-se, em primeiro plano, um homem, com aparência de cerca de 50 anos, trajando uma cartola e um sobretudo. 0 enfoque é principalmente no rosto, mas 0 recorte abrange também o busto. A única ação desempenhada pelo personagem consiste em esboçar um sorriso sutil e coçar o queixo, mantendo um aspecto facial ardiloso, repulsivo e maquiavélico, como é possível observar na figura ao lado (Fig. 1).

Figura 1 - Fotograma do trecho 1

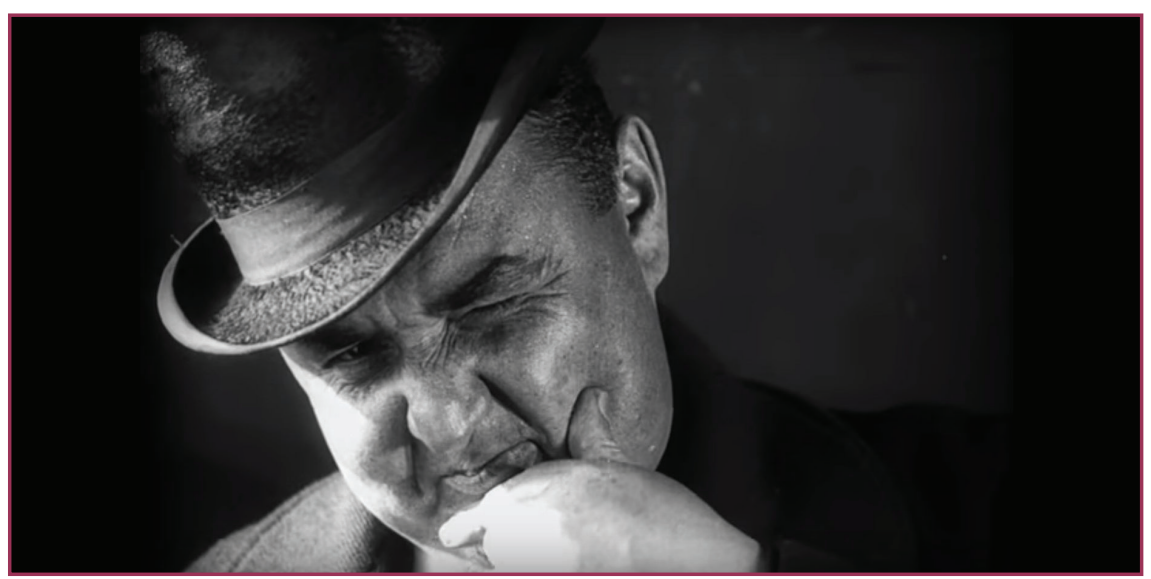

Fonte: A Greve (1925)

Essa primeira aparição não identifica ainda essa personagem como "o diretor" da fábrica. Dentro do argumento desenvolvido ao longo do filme, esta figura é constituída como "o burguês", representante do capitalismo, vilão da narrativa comunista. Não somente o papel desempenhado na trama permite identificá-lo desse modo, mas também a indumentária se presta à caricaturação típica deste que atua como representante de uma classe no discurso.

4 É difícil estimar qual teria sido o tamanho do público exposto e o impacto social, já que foi produzida e rodada num país comunista, não havendo informações do tipo "bilheteria". 
De acordo com Moscovici (2010, p.46), "representação = imagem/significação; em outras palavras, a representação iguala toda imagem a uma ideia e toda ideia a uma imagem". No caso do cinema, pode-se dizer que as representações são ideias-audiovisuais. As representações "convencionalizam os objetos, pessoas ou acontecimentos que encontram" (MOSCOVICl, 2010, p.34). Após a assimilação de uma determinada convenção representativa, as pessoas forçariam o real a assumir aquela forma, de acordo com o modelo representativo prévio, sob pena de não ser compreendido ou decodificado. Essa função das representações coincide com o significado de preconceito, usado como sinônimo por este autor.

Neste sentido, a escolha de um ator corpulento ${ }^{5}$ e gordo para representar o papel do diretor burguês-capitalista não foi irrelevante e, provavelmente, não foi casual, pois como destaca Bahiana (2012, s.p.) "[...] nada do que está na tela, em momento algum, é gratuito ou por acaso; tudo o que está na tela, a qualquer momento, tem uma razão de ser. Ou pelo menos deve ter - erros acontecem, acidentes também".

Eisenstein ficou conhecido por ser detalhista na direção e montagem de seus filmes (FIGUEIREDO, 2018; METZ, 1972). Além disso, conhecendo-se a dialética marxista (MARX; ENGELS, 2018), presume-se que a representação desta suposta "contradição" corporal entre burguesia e proletário não foi uma mera casualidade.

Como ressaltado por Melo (2011), desde o princípio, o cinema foi centrado no corpo, como a atração maior. Inevitavelmente, portanto, a "citação de uma forma fílmica passa, necessariamente, pela referência a um corpo previamente construído, o do personagem fílmico" (GUIMARÃES, 2016, p.25) - ou seja, também o corpo do ator escolhido para atuar num determinado papel é constituído nesta representação. Como destacado por Guimarães (2016, p. 21), o "[...] corpo do ator no cinema pode transbordar sua utilidade meramente representacional para ser o local de referências estéticas, ideológicas e histórico-geográficas". Pode-se acrescentar, também, referências biopolíticas, já que todo corpo carrega em si marcas políticas (FOUCAULT, 1989).

Ainda sobre essa questão, outro ponto a destacar, tratando-se de uma atuação enquanto representante dos corpulentos ou gordos, consiste no fato de que nenhum dos atores que atuaram como trabalhadores-operários eram corpulentos ou gordos. Os pontos de vista do personagem do diretor indicam que Eisenstein pretendia destacar a característica corporal de seu personagem, o que, de certo modo, evidencia uma relação entre corpo e política (FOUCAULT, 1989), politizando o corpo, já que o papel principal que este exercia na narrativa era um papel de representante político de uma classe. Esse aspecto também foi percebido por Fonseca e Paiva (2017, p. 149): "Os homens que ocupam cargos de chefia na fábrica e na polícia são os únicos personagens gordos do filme e tal característica serve para ilustrar um estilo de vida cercado de privilégios e de ostentação da riqueza" - o que dá fidedignidade à interpretação sugerida.

Como nem todo burguês era ou é gordo, esta associação pode ser considerada como preconceituosa. Ainda que espúria, a exploração dessa suposta correlação entre uma característica

50 termo corpulento foi empregado com o sentido de ter um corpo grande - fato que é exacerbado pelo uso do sobretudo na personagem do diretor. Evita-se a aplicação do adjetivo obeso unicamente para evitar anacronismos históricos, como destacado em Santolin e Rigo (2012), já que obesidade foi um termo desenvolvido posteriormente e com significados variáveis ao longo da história, fixando-se conceitualmente com base no Índice de Massa Corporal (IMC). Como não se pode medir massa corporal e estatura de representações cinematográficas, é melhor usar outros termos ao invés de obesidade por precisão linguístico-conceitual e histórica. O termo gordo, por exemplo, é menos técnico, mais relativo, e pode-se dizer com menor grau de contestabilidade que 0 ator que atuou como diretor não somente era corpulento, mas também tinha uma aparência relativamente gorda. 
corporal e certa posição socioeconômica e político-ideológica nos discursos comunistas pode ter impulsionado a difusão dos novos valores atribuídos à corpulência e à gordura corporal.

Após esse primeiro trecho, ainda no início, a trama apresenta uma fábrica e seus trabalhadores atuando, mas, como a primeira chamada indica, "um conflito está sendo engendrado", o que corresponde, de modo representativo, à "luta de classes" no argumento comunista. Os operários são apresentados mobilizando-se, a cochichar, como a conspirar. A conspirata chega aos ouvidos dos supervisores, que levam a informação ao diretor.

O segundo trecho, que começa com a chamada "O diretor" (4 min. $8 \mathrm{~s}$.), dura $1 \mathrm{~min}$. Após a chamada inicial, segue-se um plano com vista lateral, bastante rápido (2 s.), do mesmo personagem corpulento inicial, sentado, realizando um giro numa cadeira e ficando de frente para a mesa, mas de lado para o espectador. Agora o ponto de vista pega a imagem do personagem do diretor da cintura para cima, ressaltando ainda com mais ênfase sua rotundidade abdominal, como pode ser observado na figura acima (Fig. 2), o que parece ter sido um dos objetivos o optar por esse ponto de vista.

Figura 2 - Fotograma "a" do trecho 2

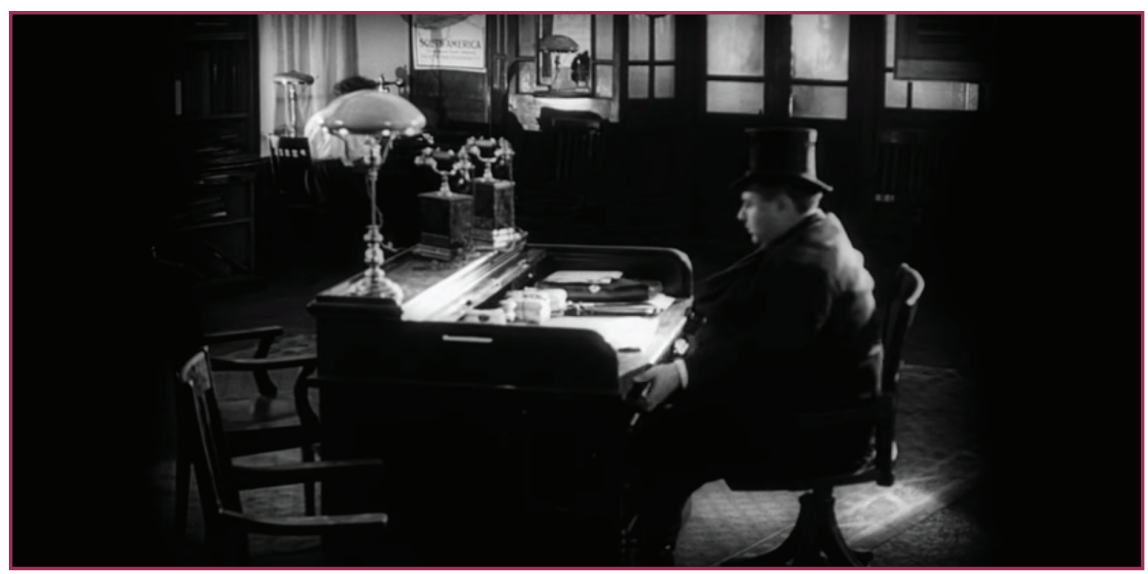

Fonte: A Greve (1925)

O plano seguinte dura $12 \mathrm{~s}$., ampliando-se ainda mais o enquadramento, permitindo ver um escritório. O personagem termina o giro, iniciado no plano anterior, afasta um tampo da mesa, retira sua cartola e deposita-a sobre a mesa, reclina-se acomodadamente na cadeira, girando-a, ficando de costas para o espectador, enquanto bafora um charuto. 0 ponto de vista permite ver que, além de corpulento e gordo, é um homem calvo e, aparentemente, de baixa estatura, pois os pés não tocam no chão após reclinar a cadeira. Apesar disso, os movimentos corporais não são lentos, mas vigorosos. Assim como o vestuário, o gestual, a posição de diretor, etc. são apresentadas para reforçar uma representação de poder. Um secretário abre a porta ao fundo da sala e anuncia a presença dos supervisores e do gerente, ao que o diretor gesticula, autorizando-o a entrar. O plano termina com os supervisores caminhando até a frente da mesa.

Um plano intermediário curto apresenta uma moça datilografando e em seguida retomase o plano frontal do diretor a baforar e, posteriormente, a perguntar o que seus subalternos querem. Eles relatam a movimentação operária e, no próximo plano, retoma-se a visão do 
diretor, que escuta os informantes, e aparece pensativo por um segundo, quando irrompe sua reflexão, arremessando seu cigarro para o lado. Em seguida, um plano curtíssimo da mão do diretor batendo na mesa, entrecortado por um plano em que uma secretária datilografa. Novo plano com nova pancada na mesa e mais um plano da secretária. Após isso, a secretária sai da sala e novo plano de $2 \mathrm{~s}$., frontal da cara e do busto do diretor resmungando, demonstrando ter ficado furioso (Fig.3). Um novo plano, lateral, entrevisto pela porta, da sala, apresenta 0 diretor irascível, batendo na mesa, enquanto os supervisores se mostram amedrontados. Estes saem, enquanto 0 diretor se dirige para a porta através da qual está a câmera. Abre a porta, fechando-a atrás de si e se desloca até um telefone, terminando a cena desta sequência analisada com um plano de texto com os dizeres "através da hierarquia!", que se refere ao fato do dono da fábrica recorrer às autoridades do aparato jurídico-policial estatal para reprimir o movimento grevista.

Figura 3 - Fotograma "b" do trecho 2

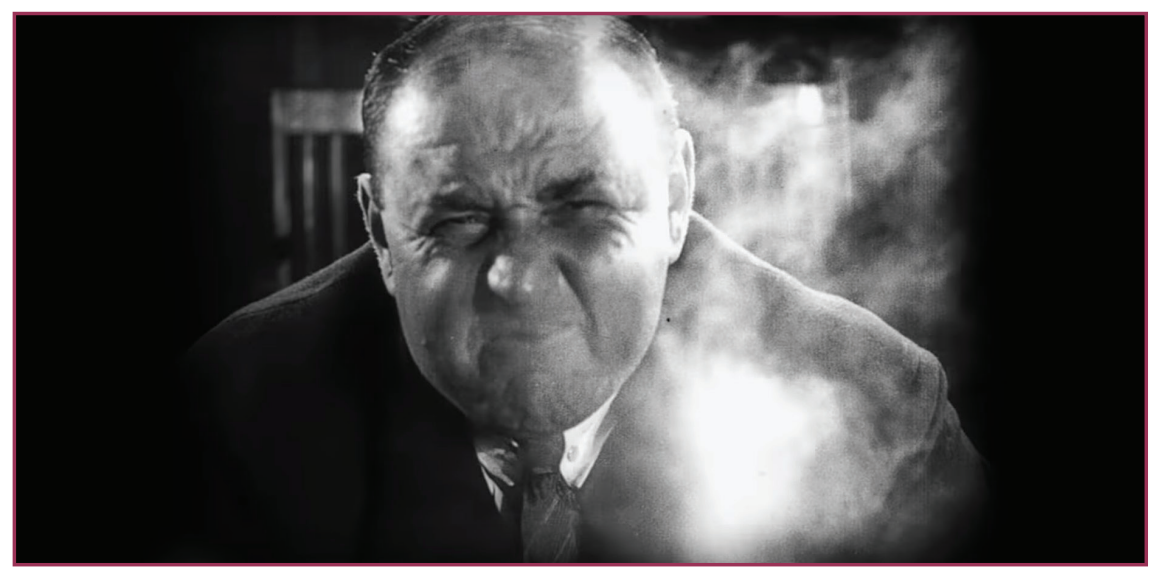

Fonte: A Greve (1925)

As associações neste trecho coadunam-se à uma concepção antiga, prévia à inversão valorativa, em que era atribuída uma suposta irascibilidade como característica dos sujeitos considerados corpulentos, tidos como sanguíneos ou pletóricos, dentro da teoria dos quatro humores na medicina medieval (SANTOLIN, 2012; SANTOLIN e RIGO, 2012b).

Pode-se argumentar que a representação de irritação do diretor não seria uma característica associada à corporeidade, mas pela greve. Assim, do primeiro trecho, prévio ao movimento grevista, em que o personagem é representado com aparência de maquinador, sucede-se um perfil irascível com a deflagração da greve indesejada por ele. Apesar de parecer ter sido realmente essa a intenção discursiva do filme, outras associações estão presentes na representação e acabam por compor uma integridade representativa, da qual muitos espectadores poderiam e podem não perceber, mas ser influenciado, levando a difusão de ideias, independentemente da intenção do autor da obra (ECO, 2005).

No terceiro trecho, em 29 min. 54 s., o diretor aparece novamente, num plano curto, de $8 \mathrm{~s}$., num enquadramento frontal, a certa distância, dos joelhos para cima, posicionado entre duas portas entreabertas, a reduzir a largura do corredor e aumentar a percepção de rotundidade do corpo do diretor, que aparece com a mão direita no bolso da sobrecasaca (Fig. 4). A escolha deste local como cenário não cumpriu nenhum papel nos acontecimentos 
narrados e parece ter servido unicamente para o propósito de aumentar a percepção relativa de corpulência do personagem.

Figura 4 - Fotograma representativo do trecho 3

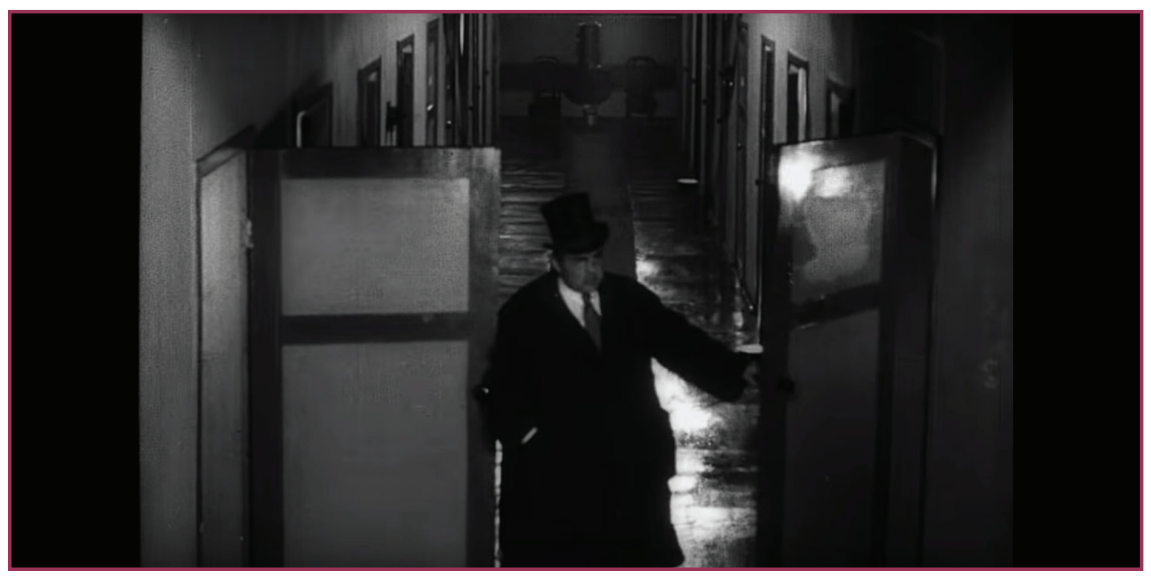

Fonte: A Greve (1925)

A ação do diretor consiste em balançar nervosamente com a mão esquerda uma das portas, enquanto aponta para os supervisores e gerente, que adentram o quadro, correndo em direção ao chefe.

Novamente, tem-se um reforço das ideias audiovisuais exploradas no primeiro e segundo trechos em que se analisaram as representações da personagem do diretor corpulência e irascibilidade. Também é notável que toda vez que ele aparece uma trilha sonora específica e repetitiva é tocada - fato que sublinha ainda mais o desejo do cineasta de dar destaque à recorrência comportamental caricaturada. Conforme Xavier (2014, p.133), no cinedialética eisensteiniano

[...] a estratégia de repetições do mesmo fenômeno, bastante frequente em suas montagens, é vista por ele como instrumento retórico para desenvolver a situação em conceito, para superar a primeira fase de leitura e propor o salto para uma nova qualidade, a do pensamento abstrato.

Vinculações como essas podem deitar raízes em períodos históricos anteriores, em que enunciações discretas e sutis, como a repetição de uma trilha sonora vinculada a um personagem gordo, podem ser interpretadas como fixidez, aversão à mudança, incapacidade de se adaptar e insistência em padrões. Gomes (2006) destaca que a obesidade na contemporaneidade remete à ideia de lentidão, peso, não fluidez e obstáculo ao movimento.

O diretor aparece novamente a partir de $37 \mathrm{~min} .14 \mathrm{~s}$., que se constituiu como quarta sequência analisada, de duração de $38 \mathrm{~s}$., filmado quase de lado, sozinho, sentado numa mesa, num ambiente aberto, como pode ser observado na figura ao lado (Fig. 5). Descarta 0 cigarro, apanha a taça de vinho, toma um gole, expressa desgosto e arremessa furiosamente fora o conteúdo, como símbolo de desperdício de comida por opulência. O plano seguinte é de uma visão frontal, da cintura para cima, recostado numa cadeira, com a mão direita dentro da sobrecasaca. Uma mão de um serviçal aparece no lado esquerdo da tela e entrega-lhe um papel, que o diretor observa e deita sobre a mesa. 0 mesmo se repete várias vezes, alternando os lados, e o diretor demonstra irritação. A legenda explica que são contas. Como os 
trabalhadores estão em greve, a fábrica parou a produção, mas as contas continuam a chegar. Uma nova conta é depositada sobre as anteriores e a mão enfia uma faca raivosamente sobre todas.

Figura 5 - Fotograma representativo do trecho 4

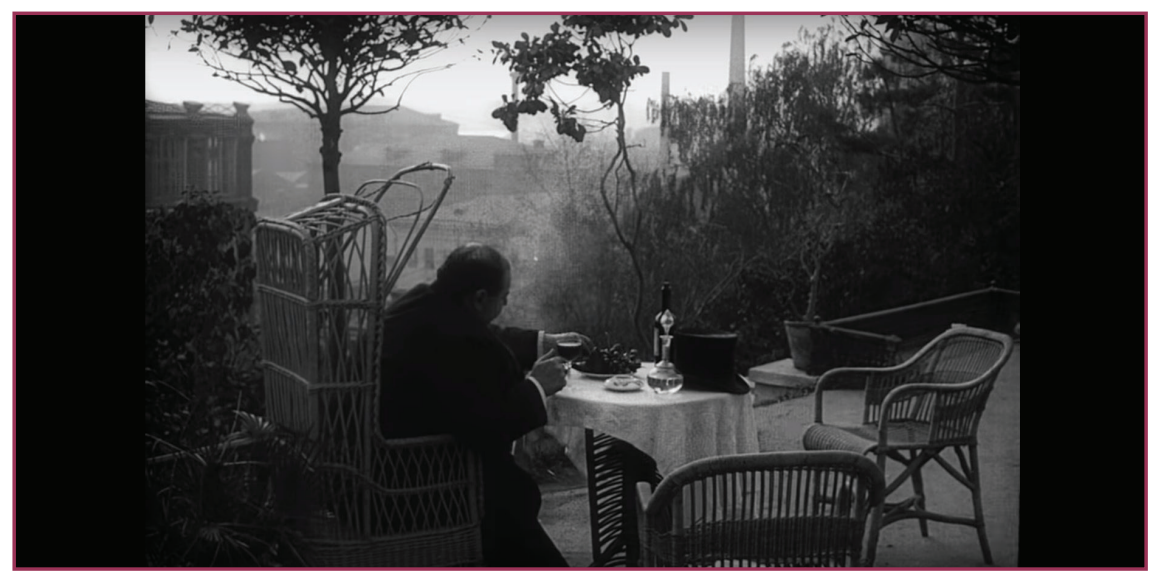

Fonte: A Greve (1925)

Um plano intermediário, de 1s., apresenta o diretor de perfil, do busto para cima. No plano seguinte, em continuidade, abre-se o enquadramento, para uma varanda. $O$ personagem, já de pé, arremessa uma cadeira sobre a árvore, à direita, e depois chuta uma segunda cadeira escadaria abaixo.

A característica principal imprimida ao personagem para este trecho foi, mais uma vez, a irritação. Mas, secundariamente, aparece também o aspecto perdulário, contraposto à miséria cada vez maior dos trabalhadores-operários, apresentada em outros trechos, à medida que a greve perdura.

Por fim, com base nas descrições, interpretações e análises expostas dos quatro trechos, pode-se considerar que o filme em questão desenvolveu algumas enunciações pertinentes à história das representações da obesidade no cinema:

$1^{0}$ - Os burgueses são corpulentos e gordos - e, inversamente, os corpulentos e gordos são burgueses.

O adjetivo "burguês" se situa na ideologia político-econômica comunista (MARX; ENGELS, 2018), o que destaca a associação entre tais características corporais e uma posição político-ideológica. Esse enunciado também comporta sentidos inversos, tais como: os proletários são magros.

Se Palma et al. (2012) denunciaram um traço fascista na abordagem da obesidade no ideário de saúde contemporâneo, o que se delineou nesta pesquisa foi mais um traço comunista/socialista - não menos totalitário - forjador de estereótipos e preconceitos perante os indivíduos corpulentos em um determinado contexto sócio-histórico. Desse modo, podese intuir que a corpulência do burguês-gordo é representada como reflexo de uma disfunção não propriamente corporal, mas social, vista como metáfora adiposa do acúmulo de capital, considerado como proveniente da exploração dos trabalhadores - do mesmo modo, o burguês 
engorda por extrair uma "mais-valia alimentar" aos operários proletários, que, por isso, não teriam comida suficiente e são representados magros.

Vale a pena pontuar que, no final do século XX, o perfil socioeconômico daqueles que são considerados obesos se inverteu em países considerados desenvolvidos, passando a acometer mais indivíduos dos estratos inferiores. Já em nações subdesenvolvidas ou em desenvolvimento, como no Brasil, essa inversão ainda não ocorreu ou só ocorreu apenas parcialmente (POULAIN, 2014).

$2^{\circ}$ - Os burgueses-gordos são irascíveis

Como destacado, as representações cinematográficas atuam como ideias audiovisuais, com alto poder de convencimento, que podem compor formações discursivas de enunciados plenos de positividade, levando a associações múltiplas na criação de um personagemrepresentante caricatural. Ainda que a irascibilidade do personagem tenha sido mais pelo movimento grevista, a composição da persona pode ter impactado no modo como os espectadores realizam associações - mesmo aquelas preconceituosas.

Também esta associação, entre corpulência ou gordura corporal excessivas e irascibilidade, inverteu-se ao longo do século XX, passando a ser vista como condição que causa inaptidão física, pacificidade, lerdeza, moleza e passividade (GOMES, 2006). Atualmente, portanto, dificilmente se atribuiria irascibilidade aos indivíduos gordos, situando esse enunciado em seu momento de emergência, ainda marcado por concepções ideológicas a respeito da corpulência dos momentos históricos anteriores à inversão valorativa.

\section{CONSIDERAÇÕES FINAIS}

Conforme Xavier (2014, p.134), ao longo da década de 1930, Eisenstein teria se reposicionado, chegando a declarar a tarefa de "corrigir excessos" e de superar a "doença infantil do esquerdismo". "Recusando-se a espelhar o mundo em sua imediata facticidade, o cinema intelectual pode ser reduzido a um espelhamento da consciência, que percebe, imagina ou pensa" (XAVIER, 2014, p.136) e, indiretamente, portanto, o produto fílmico reflete o zeitgeist ${ }^{6}$ de seu locus de emergência, funcionando perfeitamente enquanto fonte histórica primária, ainda que limitada em suas condições de possibilidade discursivas.

Ainda que diminuta enquanto composição de um quadro histórico mais pleno, a peça cultural pode integrar uma série histórica mais ampla - se congregada a outras do mesmo tipo no sentido de verificar recorrências e possibilitar a identificação de formações discursivas mais amplas nas representações da obesidade. Isso pode ser feito não somente no Cinema Soviético, na década de 1920, mas também na história do cinema como um todo.

Apesar de ainda serem escassas no Brasil, as pesquisas sobre a história da obesidade na perspectiva das Ciências Humanas são essenciais para compreender melhor essa temática. Abordagens desse tipo vêm se tornando, nos últimos anos, promissoras nos chamados fat studies, em que já há iniciativas relacionadas às representações cinematográficas, tal como a de Pistone (2015) - mas que se concentraram, diferentemente do nosso estudo, em filmes mais recentes ${ }^{7}$. 
Ainda que imersos numa contemporaneidade gordofóbica, que turva nossa visão de outras épocas, buscou-se, em certa medida, contar uma história do presente, como num futuro que ainda não ocorreu, e que não cabe antecipá-lo, mas que pode se realizar, de reversão valorativa.

Futurologia à parte, houve condições que outrora foram, a priori, problematizadas patologicamente, e, posteriormente, despatologizadas, tais como nos conta Foucault (2001) a respeito da masturbação e a homossexualidade, podendo vir a ocorrer o mesmo com a obesidade. Por ora, entretanto, cabe historiografar o processo de inversão valorativa que possibilitou que a corpulência fosse patologizada, e os diferentes dispositivos de veridição utilizados para difundir esses valores e suas verdades. Assim, a hipótese de que o cinema possa ter contribuído como uma das estratégias utilizada para construir verdades históricas sobre a obesidade mostra-se promissora.

\section{REFERÊNCIAS}

A GREVE. Direção Serguei Eisenstein, Produção Boris Mikhin, URSS, 1925, 82 minutos, preto e branco. Disponível em: https://www.youtube.com/watch?v=VD40vLjRaNA. Acesso em: 5 jun. 2018.

BAECQUE, Antoine. Le discours anti-noble (1787-1792) aux origines d'un slogan: "Le peuple contre les gros". Revue d'Histoire Moderne et Contemporaine. Paris: Belin: CNRS, 1989. v. 36 , p. 3-28.

BAHIANA, Ana M. Como ver um filme. Rio de Janeiro: Nova Fronteira, 2012.

BARDIN, Laurence. A análise da enunciação. In: BARDIN, Laurence. Análise de conteúdo. Lisboa: Edições 70, 2011. Cap. 3, Pt.4, p.169-184.

BERNADET, Jean C. 0 que é cinema. São Paulo: Nova Cultural, 1985.

COUSINS, Mark. The story of film: an odyssey. Documentário baseado na obra homônima de Mark Cousins. Tradução e legenda Eduardo Friedman. Londres: BBC, 2011.

ECO, Umberto. Interpretação e superinterpretação. São Paulo: Martins Fontes, 2005.

ELLSWORTH, Elizabeth. Modos de endereçamento: uma coisa de cinema; uma coisa de educação também. In: SILVA, Tomaz T. (org.). Nunca fomos humanos: nos rastros do sujeito. Belo Horizonte: Autêntica, 200. p.7-76.

FERRO, Marc. Cinema e História. Rio de Janeiro: Paz e Terra, 1992.

FIGUEIREDO, Carlos L. O conteúdo propagandístico do Cinema Soviético: o exemplo da obra de Eisenstein. Disponível em: http://www.ipv.pt/forumedia/6/16.pdf. Acesso em: 27 jul. 2018.

FONSECA, João B.; PAIVA, Vanessa M. B. Eisenstein, o cineasta da revolução. História e Cultura, v. 6, n. 1, p. 144-160, mar. 2017. Disponível em: https://ojs.franca.unesp.br/index.php/ historiaecultura/article/view/2046 Acesso em: 27 jul. 2018. 
FOUCAULT, Michel. A arqueologia do saber. 7. ed. Rio de Janeiro: Forense Universitária, 2008.

FOUCAULT, Michel. A verdade e as formas jurídicas. Rio de Janeiro: Nau, 2005.

FOUCAULT, Michel. Os anormais: curso no Collège de France (1974-1975). São Paulo: Martins Fontes, 2001.

FOUCAULT, Michel. Poder-corpo. In: MACHADO, Roberto (org.). Michel Foucault: microfísica do poder. 8. ed. Rio de Janeiro: Graal, 1989. p. 145-152.

GOMES, Ivan M. Obesidade como metáfora contemporânea: uma "cruzada saudável" em nome do consumo e do risco. Movimento, v.12, n. 3, p. 45-71, set./dez. 2006.

GUIMARÃES, Pedro M. Corpo e citação. In: SAURA, Soraia C.; ZIMMERMANN, Ana C. (org.). Cinema e corpo. São Paulo: Laços, 2016. p.21-32.

IMDb - INTERNET MOVIE DATABASE. Disponível em: https://www.imdb.com/title/ tt0015361/?ref =fn al tt 1. Acesso em: 5 jun. 2018.

JULLIER, Laurent. MARIE, Michel. Lendo as imagens do cinema. São Paulo: Senac, 2012.

MARTIN, Laurent. Le gros comme métaphore du bourgeois dans la presse de gauche aux XIXe et XXe siècles. In: CSERGO, Julia (org.) Trop Gros? L'obésité et ses représentations. Paris: Autrement, 2009. p. 213-227.

MARX, Karl; ENGELS, Friedrich. O manifesto do partido comunista. Disponível em: http:// www.ebooksbrasil.org/adobeebook/manifestocomunista.pdf. Acesso em: 8 jun. 2018.

MELO, Victor A. Cinema e Esportes: diálogos. Revista Z Cultural: Revista do Programa Avançado de Cultura Contemporânea, v.3, n.1, 2011. Disponível em: http://revistazcultural. pacc.ufri.br/cinema-e-esportes-dialogos-de-victor-andrade-de-melo-2/. Acesso em: 19 set. 2018.

METZ, Christian. A significação no cinema. São Paulo: Perspectiva, 1972.

MOSCOVICI, Serge. Representações sociais: investigações em psicologia social. 7. ed. Rio de Janeiro: Vozes, 2010.

PALMA, Alexandre et al. Os "pesos" de ser obeso: traços fascistas no ideário de saúde contemporâneo. Movimento, v. 18, n. 4, p. 99-119, out./dez. 2012.

PISTONE, Amy. Film Not Found: Current Cinematic Representation of Fat Females and Scripting the Self. In: BSU Honors Program Theses and Projects. Item 102. 2015. Disponível em: http://vc.bridgew.edu/honors proj/102 . Acesso em: 19 set. 2018.

POULAIN, Jean P. Sociologia da obesidade. São Paulo: SENAC São Paulo, 2014.

PUBLIC DOMAIN MOVIES. Disponível em: http://publicdomainmovies.net/ . Acesso em: 19 ago. 2018.

SANTOLIN, Cezar Barbosa. 0 nascimento da obesidade: um estudo genealógico do discurso patologizante. 2012. 173 f. Dissertação (Mestrado em Educação Física) - Universidade Federal de Pelotas, Pelotas, 2012.

SANTOLIN, Cezar Barbosa; RIGO, Luiz Carlos. Por que o termo "gordo" se tornou politicamente incorreto no Brasil? In: CONGRESSO SULBRASILEIRO DE CIÊNCIAS DO ESPORTE, 
6, 2012a, Rio Grande. Anais [...]. Disponível em: http://cbce.tempsite.ws/congressos/index. php/6csbce/sul2012/trackDirector/index/submissionsAccepted. Acesso em: 7 jun. 2018.

SANTOLIN, Cezar Barbosa; RIGO, Luiz Carlos. O nascimento do discurso patologizante da obesidade. Movimento, v.21, n.1, p.81-94, jan./mar. de 2015.

SANTOLIN, Cezar Barbosa; RIGO, Luiz Carlos. A obesidade e a problematização da corpulência na Idade Média. FIEP BULLETIN, v. 82 , Sp. Ed. 2012b. Disponível em: http://www. fiepbulletin.net/index.php/fiepbulletin/article/view/2305 Acesso em: 15 jun. 2019.

SEIXAS, Cristiane M.; BIRMAN, Joel. O peso do patológico: biopolítica e a vida nua. História, Ciências, Saúde - Manguinhos, v.19, n.1, p.13-26, jan./mar. 2012,

STRUNA, Nancy L. Pesquisa histórica em atividade física. In: THOMAS, Jerry R.; NELSON, Jack K.; SILVERMAN, Stephen J. Métodos de pesquisa em atividade física. 5. ed. Porto Alegre: Artmed, 2007. p. 189-201.

XAVIER, Ismail. Eisenstein: da montagem de atrações ao cinema intelectual. In: XAVIER, Ismail. 0 discurso cinematográfico. 6. ed. São Paulo: Paz e Terra, 2014. p.129-137. 